\title{
Buddhist Çevre Eski Uygur Türkçesi Metinlerinde Yabancı Kökenli Sőzcükler Üzerine Bir Değerlendirme
}

\section{An Evaluation of Foreign Oriented Words in the Old Uighur Buddhist Peritexts}

\author{
Neslihan ÇELİK ${ }^{1}$
}

'Sorumlu yazar/Corresponding author: Neslihan Çelik (Öğr. Gör. Dr.), Yeditepe Üniversitesi, Eğitim Fakültesi, Türk Dil ve Edebiyatı Öğretmenliği, İstanbul, Türkiye E-posta: neslihan.celik@yeditepe.edu.tr ORCID: 0000-0001-6807-8187

Başvuru/Submitted: 25.08.2019 Revizyon Talebi/Revision Requested: 25.09.2019

Son Revizyon/Last Revision Received: 25.10.2019

Kabul/Accepted: 20.11.2019

Online Yayın/Published Online: 17.12.2019

Atıf/Citation: Celik, Neslihan. "Buddhist Çevre Eski Uygur Türkçesi Metinlerinde Yabancı Kökenli Sözcükler Üzerine Bir Değerlendirme." Türkiyat Mecmuası-Journal of Turkology 29, 2 (2019): 391-402.

https://doi.org/10.26650/iuturkiyat.660589 öz

Türk dili, Türk kültürünün birinci aslî unsuru ve taşıyıcısı niteliğindedir. Dil olmadan bir milletin varlığından, kültüründen ve devamlılığından söz etmek mümkün değildir. Türk dili, tarihsel hiçbir dönemde inkıta evresi geçirmemiştir ve bu durum, Türk kültürünün tarih boyunca devamlılık arz ederek günümüze ulaşmasını sağlamıştır. Türklerin farklı sosyal çevrelere dâhil olmaları, onların eserlerinde yeni kavram alanlarına ihtiyaç duymalarını beraberinde getirmiştir. Kavram alanlarına duyulan ihtiyaç, Türk dilinde türetme faaliyetlerinin etkin ve işlek kullanılması ve tercüme eserlerde belirli kavram alanlarında ödünçleme sözcüklerin varlığı ile sonuçlanmıştır. Eski Uygur Türkçesi metinleri de bu bağlamda değerlendirilmelidir.

Çalışmamızda Buddhist çevre Eski Uygur Türkçesi metinlerinden "Kuanşi İm Pusar", "Uygurca Üç Hikâye" ve "Çaştani Bey Hikâyesi" adlı eserler esas alınarak ilgili eserlerde yabancı kökenli sözcükler tespit edilecektir.

Anahtar kelimeler: Eski Uygur Türkçesi, Buddhizm, türetme faaliyetleri, yabancı sözcükler, kavram alanı

\section{ABSTRACT}

The Turkish language is the first essential element of the Turkish culture and definitely a culture bearer. It is impossible to speak of the existence, culture and continuity of a nation without language. The Turkish language historically has never been through any period of interruption, and this situation has ensured the continuation of Turkish culture through the history and its reaching the present day. The involvement of Turks in different social circles has led to the need for new conceptual fields in their works. The need for new conceptual fields has resulted in the efficient and effective use of derivation activities in the Turkish language, and the formation of new borrowed words in certain conceptual fields in the translated works. Old Uighur Turkic texts should be evaluated in this context.

Our work will be based on the works titled "Kuanşi İm Pusar", "Uygurca Üç Hikâye" and "Çaştani Bey Hikâyesi" and foreign origin words will be detected in related works.

Keywords: Old Uighur Turkic, Buddhism, derivation activities, borrowed words, conceptual field 


\section{EXTENDED ABSTRACT}

The first essential element of any culture is language, and without language it is not possible to speak of the existence of a society. Societies have developed and used new words in relation to their geography in each period. Therefore, it is possible to make general inferences about the culture of the society that speaks a language by considering the existing vocabulary. Similarly, the Turkish language reflects Turkish culture and it has been the bearer of Turkish culture for centuries. In order to talk about the existence of a cultural concept, it is necessary to mention the words related to that concept in the language of that nation.

Language has developed in relation to culture across all periods. This situation reveals that language and culture cannot be evaluated independently. In other words, literary works should not be evaluated independently of the periods in which they are written, and the social conditions and the cultural elements of the society in which they are written should be taken into consideration. In this way, while examining the works of the Old Uighur Turkish period, it is not possible to evaluate them independently from the social environment, to make sense of them and to shed light upon the conceptual fields of those words.

The Uighur Turks are a Turkish tribe with a developed civilization and have succeeded in conveying their high level of civilization up to the present day with their works in different social circles such as Manicheism, Buddhism, Christianity and Islam. As a result, Uighur Turks have played an important role in maintaining tradition. In this study, words of foreign origin in "Kuanşi İm Pusar", "Three Stories in Uighur" and "Çaştani Bey Story” which are among the texts of Buddhist environment Old Uighur Turkish have been determined. Classified words are listed alphabetically.

While determining borrowed words in Old Uighur Buddhist peritexts, Sinasi Tekin's Uyghur Texts I: Kuanşi İm Pusar, and Three Stories in Uighur translated by S. Himran and "The Story of Çaştani Bey" written by A. von Gabain and FWK Müller which was translated by S. Himran were taken as the basis.

In this study, the words of foreign origin identified in the works mentioned above are arranged alphabetically under three titles. After giving the origins and meanings of the words, the numbers indicate the line number of the word in the text. 


\section{Eski Uygur Türkçesinin Türk Dili Tarihi İçerisindeki Yeri ve Rolü}

Türk dili tarihsel bütün dönemlerinde herhangi bir kesintiye uğramadan günümüze kadar gelmiştir. Bu durum Türk dilinin, konuşulduğu coğrafyalarda resmî dil olarak kullanımının doğal bir sonucu olarak karşımıza çıkmaktadır. Türk tarihi tamamıyla sülaleler tarihidir. Hâkim olan boy diğer boyları bir araya getirir ve devleti tesis eder, devlet de edebî dilini kendi siyasî coğrafyasında 'resmî dil' konumuna getirerek, kültürünün temel taşıyıcısı olarak kullanır. Köktürk Kağanlığı bu durumun en somut örneklerinden birini teşkil etmektedir. Köktürk Kağanlığ 1 bir Türk Konfederasyonudur ve bu konfederasyonu oluşturan her boy kendi bulunduğu coğrafyada kendi yazılı dilini kullanırken devletin resmî dili olarak ise bu konfederasyonda demografik olarak en kalabalık boy durumunda olan Oğuzların yazılı dilini kullanmışlardır. Konuşma dilinin yazılı dilden yazı diline geçişinde asıl etken güçlü devlet hâkimiyetidir. Bu durum Köktürklerden başlamak üzere Türk dilinin tarihsel her dönemi için geçerlidir. Doğuda Türk boyları ittifakının gerçekleştiği Köktürk devletinin birinci hanedanlığı döneminde Türk dili konuşma dili seviyesinden yazılı dil seviyesine ulaşmış, hatta devlet dili olma özelliği kazanarak yazı dili olmuştur. Bu durum ikinci hanedanlık döneminde de pekiştirilmiştir. Daha sonra İslamiyet'in kabulü ve sonrasında tek merkezli Ötüken'in yerini çok merkezli idari yapıların almasıyla birlikte, boylar kendi yazılı dillerini kullanmışlar ve kendi bulundukları coğrafyada hâkim güç olma yoluna gitmişlerdir. Karahanlı sülâlesinin hâkimiyeti döneminde siyasî erkin tek merkezli yönetimden uzaklaşması beraberinde resmî yazı dili olma özelliğini tarihsel bütün dönemlerde muhafaza eden Türk dilinin yalnızca edebî dil olarak varlığını devam ettirmesine sebebiyet vermiştir.

Köktürk Kağanlı̆̆ döneminde yazılı dil statüsünde bulunan Uygur Türkçesi, Köktürk Kağanlığının tek merkezli hâkimiyetini yitirmesinin ardından 8. yüzyılın sonlarından itibaren yazı dili seviyesine ulaşmış ve Çin'in Kansu ilinin kuzey batısında 18. yüzyılın sonlarına kadar resmî yazı dili olarak varlığını sürdürmüştür. Uygur Türklerinin Köktürk Kağanlığını oluşturan boylardan biri olduğu ve Köktürk Kağanlığının sona ermesinin ardından çok farklı coğrafyalara dağılmadıkları göz önünde bulundurulursa, Eski Uygur Türkçesi ile Köktürkçe arasında yapısal olarak farklılıkların olmadığı görülmektedir. Türk dili tarihsel bütün dönemlerde yazı dili olma özelliğini koruduğu için yapısal olarak hiçbir kesintiye ve ciddi farklılıklara uğramadan günümüze kadar gelebilmiştir.

Uygur Türkleri, farklı inanç sistemlerinin çevrelerine girmelerinin etkisiyle karşılarına yeni çıkan kavram alanlarını karşılamak üzere türetme faaliyetlerinde bulunmuşlar ve Türkçenin yapısına aykırı olmamak kaydıyla Türkçe sözvarlı̆ğnı kullanarak yeni sözcükler türetmişlerdir. Bu sebeple Eski Uygur Türkçesi, yapım ekleri bakımından oldukça zengindir. Eski Uygur Türkçesini Köktürkçeden ayıran en önemli husus, bahsedilmekte olan bu türetme faaliyetlerinin yoğunluğu nedeniyle bu dönemde Türk diline birçok yeni sözcüğün kazandırılmış olmasıdır. Bununla birlikte, Uygur Türkçesinin söz dizimi Türk dilinin genel kurallarına uygundur. Bu durum, Türk dilinin tarihsel bütün dönemlerde resmî yazı dili statüsünde kullanılmış olmasının 
doğal bir sonucu olarak karşımıza çıkmaktadır. Türk dili tarihsel hiçbir dönemde yapısal değişikliğe uğramamış ve günümüze kadar gelmiştir.

Karahanlı ve Harezm Türkçelerinin temeli Uygur edebî dilidir. Karahanlı Türklerinin girdikleri farklı sosyal çevreye ait kavram alanını oluşturan sözcükler dışında Uygur Türkçesi ile Karahanlı Türkçesi arasında ciddi farklılıklar bulunmamaktadır. ${ }^{1}$ Kaşgarlı Mahmud da, "Uygur şehirlerine varıncaya dek, Ertiş, Ila, Yamar, Etil ırmakları boyunca oturan halkın dilinin doğru Türkçe olduğunu söylemiş, bunların en açık olanının Hakaniye ülkesinin halkının dili olduğunu yazmıştır. ${ }^{2}$ 15. yüzyılda ortak yazı dili olan Doğu Türkçesinin de temelinde Uygur Türkçesi vardır. Bu dönemde belirleyici rol oynayan Ali Şir Nevâyî, Doğu Türkçesinin temelini Uygur yazı diline dayandırmıştır. Boy birliğinin sağlanmış olması, dil birliğinin sağlanmış olduğunu kanıtlar niteliktedir. Bunun sonucu olarak, Doğu Türklük sahasında ortak yazı dilinin Batı Türklük sahasından önce sağlanmış olduğu ifade edilebilmektedir. Nitekim Türk edebiyatının bilinen ilk şairler tezkiresi olan Mecâlisü'n-Nefâis' in ${ }^{3}$ Doğu Türklük sahasında kaleme alınmış olması söz konusu durumu tanıklatmaktadır.

Tek merkezli Ötüken'in elden çıkması ve buna bağlı olarak tek merkezli siyasî yapının yerini çok merkezli yapılara bırakmasının ardından resmî yazı dili statüsünü kaybeden Köktürkçe, yerini Uygur Türkçesine bırakmıştır. Buna bağlı olarak, Köktürkçe, dil mirasını Uygur Türkçesi üzerinden devam ettirmiş ve Uygur Türkçesi de Türk dilinin günümüze kadar kesintiye uğramadan gelmesini sağlamıştır.

\section{Uygur Türklerinin Girdikleri Farklı Sosyal Çevreler ve Buna Bağlı Olarak Uygur Türkçesindeki Türetme Faaliyetleri}

Kültürün birinci asli unsuru dildir ve dil olmadan da bir toplumun varlığından söz etmek imkânsızdır. Toplumlar, her dönemde yaşadıkları coğrafyayla ilintili olarak yeni sözcükler türetmişler ve kullanmışlardır. Bu nedenle bir dilin mevcut söz varlığına bakılarak o dili konuşan toplumun kültürü hakkında genel çıkarımlar yapılabilmektedir. Benzer olarak, Türk dili de Türk kültürünü yansıtmakta ve Türk kültürünün taşıyıcısı görevini yüzyıllardır sürdürmektedir. Kültürel bir kavramın varlığından söz edebilmek için o milletin dilinde o kavramla ilgili sözcüklerin varlığından söz etmek gerekmektedir.

Uygur Türkleri farklı sosyal çevrelere girmişlerdir. Buddhizm, Maniheizm ve Şamanlık Uygur Türklerinin yaşadıkları coğrafyada yerleşmiştir. ${ }^{4}$ Tarihsel bütün dönemlerde girilen sosyal çevreyle beraber ihtiyaç dâhilinde sözcük türetme faaliyetleri yapılmıştır. Uygur Türkçesi dönemi bunun en somut örneği olarak gösterilebilmektedir. Maniheizm ve Buddhizm inanç sistemlerinde okumak ve okutmak sevap olarak kabul edildiğinden bu dönemde birçok eser tercüme edilmiştir. Nitekim Türk dilinin hiçbir tarihi döneminde inanç sistemlerine dair telif

\footnotetext{
Ahmet Bican Ercilasun, Başlangıçdan Yirminci Yüzyıla Türk Dili Tarihi, (Ankara: Akçă̆ Yayınları, 2017), 342. Ahmet Bican Ercilasun ve Ziyat Akkoyunlu, Divânu Lugâti 't-Türk (Ankara: Türk Dil Kurumu Yayınlar1, 2014 ), 11. Kemal Eraslan, Mecâlisü’n-Nefâyis (Ankara: Türk Dil Kurumu Yayınları, 2001).

Zeki Velidi Togan, Umumî Türk Tarihine Giriş, (İstanbul: Enderun Kitabevi, 1981), 2: 100.
} 
eserlere rastlanılmamaktadır. Eski Uygur Türkçesi döneminde de farklı inanç çevrelerine girilmesiyle beraber tercüme eserlerin ön plana çıkması dolayısıyla yeni kavram alanlarına ihtiyaç duyulmuş ve bu durum beraberinde yeni sözcükler türetme ihtiyacını doğurmuştur.

Dil, bütün dönemlerde kültürle ilintili olarak gelişim göstermiştir. Bu durum, dil ve kültürün birbirinden bağımsız değerlendirilemeyeceğini ortaya koymaktadır. Diğer bir ifade ile eserler ele alınırken yazıldıkları dönemlerden bağımsız değerlendirilmemeli, kaleme alındığı sosyal şartlar ve yazıldığı toplumun kültürel unsurları göz önünde bulundurulmalıdır. Nitekim Eski Uygur Türkçesi dönemi eserleri incelenirken onları sosyal çevreden bağımsız olarak değerlendirmek, eserleri yeniden anlamlandırmak ve sözcüklerin kavram alanlarına ilişkin açıklamalarda bulunmak mümkün değildir.

Türkler, gittikleri her yerde kültür merkezleri oluşturmuşlardır ve dâhil oldukları sosyal çevrelere göre farklı yazı sistemleri kullanmışlar ve geliştirmişlerdir. Arat, Türk milletinin kendi kültür ihtiyacını karşılamak için tarihin farklı devirlerinde farklı alfabeler yarattıklarını ya da var olan alfabeleri benimseyerek, onları kendi kültür hayatlarında bir vasıta olarak kullandıklarını ifade etmiştir. ${ }^{5}$ Burada dâhil olunan sosyal çevrelerden kasıt, kabul edilen inanç sistemleri ve dinlerdir. Benimsenen her inanç sistemi ve din beraberinde yeni bir harf sistemini de getirmiştir. Nitekim Türkler, girdikleri farklı sosyal çevrelerle beraber Türk-Runik, Soğut, Mani, Brahmi, Arap, Süryani ve Latin alfabelerini kullanmışlardır. Bu noktada dikkat edilmesi gereken husus, her bir yazı sisteminin yeni bir dil anlamına gelmemesidir.

Uygur Türkleri, medeniyet bakımından gelişmiş bir Türk boyu olup sahip oldukları yüksek medeniyet seviyelerini Maniheizm, Buddhizm, Hıristiyanlık ve İslamiyet gibi farklı sosyal çevreler dâhilinde verdikleri eserlerle günümüze kadar iletebilmeyi başarmışlardır. Bunun bir sonucu olarak, Uygur Türkleri, geleneğin devamının sağlanmasında önemli rol oynamışlardır. Uygur Türkçesi döneminde ortaya konulan eserler farklı inanç sistemlerinin birer mahsulleridir ve Uygur Türkçesi döneminde türetme faaliyetlerinin yaygın bir şekilde karşımıza çıkması farklı inanç sistemlerinin beraberinde getirdiği kavram alanlarına dair ihtiyaçtır.

\section{Buddhist Çevre Eski Uygur Türkçesi Metinlerinde Yabancı Kökenli Sözcüklerin Varlığı}

Yukarıda da zikredildiği gibi Eski Uygur Türkçesi dönemi eserleri, farklı inanç sistemlerinin mahsulleridir. Farklı inanç sistemlerine ait farklı dillerde yazılmış eserler bu dönemde Uygur Türkleri tarafından Türkçeye tercüme edilmiş ve yine yukarıda ifade edildiği gibi yeni kavram alanlarına dair ihtiyaçlar beraberinde sözcük türetme faaliyetlerini de getirmiştir. Diğer ifade ile Türk dilinin yapısına uygun sözcük türetme faaliyetleri bu dönemde etkin ve işlek bir biçimde yapılmıştır.

Bu çalışmamızda, Buddhist çevre Eski Uygur Türkçesi metinlerinden "Kuanşi İm Pusar”, "Uygurca Üç Hikâye” ve "Çaştani Bey Hikâyesi” adlı eserlerdeki yabancı kökenli sözcükler

5 Reşit Rahmeti Arat, "Uygur Alfabesi”, Makaleler içinde, I, (Ankara 1987), 674-699. 
tespit edilmiştir. Tasnif edilen madde başı sözcükler, alfabetik listelenmiştir.

Buddhist Çevre Eski Uygur Türkçesindeki ödünçleme sözcükleri tespit edilirken Şinasi Tekin'in Uygurca Metinler I: Kuanşi Im Pusar ${ }^{6}$ adlı eseri, A. von Gabain ve F. W. K. Müller'in hazırlamış olduğu S. Himran'ın çevirdiği Uygurca Üç Hikâye adlı eser ve A. von Gabain ve F. W. K. Müller'in hazırlamış olduğu S. Himran'ın çevirdiği Çaştani Bey Hikâyesi ${ }^{8}$ adlı eser esas alınmıştır.

\subsection{Yabancı Kökenli Sözcükler}

Buddhist çevre Eski Uygur Türkçesi metinlerinden Kuanşi İm Pusar, Uygurca Üç Hikâye ve Çaştani Bey Hikâyesi adlı eserlerde tespit edilen yabancı kökenli sözcükler aşağıda üç ayrı başlık altında alfabetik olarak dizilmiştir. Sözcüklerin kökenleri ve anlamları verildikten sonra yer alan rakamlar, ilgili sözcüğün metin içerisindeki satır numarasını göstermektedir.

\subsubsection{Kuanși İm Pusar'da Tespit Edilen Yabancı Kökenli Sözcükler}

ajun // azun (Soğd. ajun), dünya; Buddhizm inanışına göre çile doldurmak üzere başka başka kılıklarda doğan ruhun her doğuştaki şekli, bağlandığı cisim, 191

aryavalokdişvar (Skr. āryāvalogiteşvara), 7-8

asur (Skr. asura), cin, 142

bişamn (Skr. vaişramanga/vaişravanga), 120, 121

bodisvt (Skr.) Bodhisattva, "pek yüksek erenler" gibi bir anlamda olup lakap olmakla ait olduğu isimden sonra gelir. 7, 10b, 13, 24, 52, 84, 104, 173, 203, 84, 59, 70, 83, 88, 97, 101, $148,154,160,164,171,176,84,213$

bramn (Skr. brāhmanga), 131, 132

burk̦an (Çin.), Buddha, Peygamber, 97, 168, 169, 171, 213, 102, 103, 179, 168, 90, 97, $100,162,171,175,213,169,218,221$

buşı (Çin. pu-shi), sadaka; altı ya da on faziletten biri, 158, 165, 161, 53, 153, 166

but (Skr. buddha), bk. burk̦an, 1, 222

çambudvip (Skr. jambudvipa), Bu dünyanın adı, 98

drm (Skr. dharma), 1, 222

drmuruç (Skr. dharmaruci), fazilet sahibi, 223

erdni (Skr. ratna), cevher, kıymetli eşya, 19, 167, 157, 18, 168

ezrua (Soğd.) Burkancılarda brahman, 108, 109, 204

gaij (Skr. gangā), Ganj nehri, 84

gantar (Skr. ganthāra), 142

6 Şinasi Tekin, Uygurca Metinler I: Kuanşi İm Pusar (Erzurum: Atatürk Üniversitesi Yayınları, 1960).

7 A. von Gabain ve F. W. K. Müller, Uygurca Üç Hikâye, çev. S. Himran (Ankara: Türk Dil Kurumu Yayınları, 1946).

8 A. von Gabain ve F. W. K. Müller, Çaştani Bey Hikâyesi, çev. S. Himran (İstanbul: Bürhaneddin Erenler Basımevi, 1945). 
gintirvi (Skr. gantharva), 142

gntr (bk. gantar) B23

gntrv (bk. gintirvi) A142

Ķormuzta (Soğd.) Hormuzta İndra ilahı, 110, 111

klp (Skr. kalpa), bir devir adı, 94, 178

kolti (Skr. koši), en yüksek say1, on milyon, 178

koti (Skr. koši), en yüksek sayı, on milyon, 84

ķuanşi im (Çin. kuan-ş1-yin), 8, 13, 176, 2, 10a, 14, 22, 25, 32, 39, 51, 55, 58, 60, 62, 64, $67,70,74,79,82,90,94,98,103,105,107,109,111,113,116,120,123,125,128,130,132$, 134, 137, 140, 144, 146, 148, 149, 157, 159, 162, 166, 169, 174, 192, 207, 214, 218

lu (Çin. lung), ejderha, 142

luu (Çin. lung), ejderha, D5

maǵuruk (Skr. mahoraga), büyük yılan, 143, B 23, D6

mgiş̧var (Skr. maheşvara), 116, 115, A115, A116

namo (Skr. namağ), sayg1, 1, 222, 55

nızvanı (Soğd.), günah, 203

nom (Soğd.), kanun, 158, 99

nomçı (Soğd. nom + T. -çı), vaiz, 127, 128

nomla- (Soğd. nom + T. -la-), dini öğretmek, anlatmak, 99, 104, 106, 108, 110, 112, 114 , $117,119,121,124,126,128,131,133,136,139,141,147,94,177,180,145,219$, A104, A121, A136, A139, A141, B6, D 11

noş (Soğd.) iksir, 202

pratikabut (Skr. pratyekabuddha), 104, 106

prtikabut (Skr. pratyekabuddha), B28, B 29

prit (Skr. preta), ruh, hayalet, 191

pusar (Skr. bodhisattva), 2, 14, 22, 25, 32, 39, 51, 56, 58, 60, 62, 64, 67, 82, 91, 95, 98, $103,105,107,109,111,113,116,120,123,125,128,130,132,134,137,140,144,146,149$, $159,166,169,174,192,207,215,218,70,79,155,74,163,157,10 \mathrm{a}$

saij (Skr. sangha), rahipler topluluğu, 1, 222

sartbav (Skr. sārthavāha), kervan başı, kılavuz, 45, 48

sav (Skr. sahā-(a)), 151

şakimun (Skr. şākyamuni), Burkan'ın asıl adı, 168

şiravak (Skr. şrāvaka), A106

şlok (Skr. şloka), beyit, 171, 175

şmnanç (Skr. şramaneri), rahibe, 133, 135

şravak (Skr. şrāvaka), 106, 108

şrvk (Skr. şrāvaka), B 29, B 31

tamu (Soğd. tamu), cehennem, 191 
tay (Çin. tai), 117, 119

taysukin (Çin.), A 117, A119

toym (Çin. tao-jên), rahip, 133, 135

tsun (Çin. ts’un), küçük, ufak, zayıf, 28

tsuy (Çin. tsui), günah, 200

upasanç (Skr. upāsikā), 133, 134, 135

upasi (Skr. upāsaka), 223, 133, 135

vçirpan (Skr. vajrapāngi), şimşekten kamayı elinde tutan, 145, 147

vidya (Skr. vidyā), bilgi; büyü sanatı, 219

\subsubsection{Uygurca Üç Hikâye'de Tespit Edilen Yabancı Kökenli Sözcükler}

amarl (?) kimi, kimisi, bazısı C 30

arjavrt (?) Lacivert, B 49

$\operatorname{arzl}$ (Skr. rşi), veli, münzevi, C 59

asanki (Skr. asamkhyeya), Zaman mesafesi (felsefî 1stılahtır.) B 43, C 186, C 191, C 194, C 197

avış (Toh. aviş; Skr. avici), En alttaki cehennemin adı, C 154, C 157, C 172, C 158

azun (Soğd. ajun), dünya; Buddhizm inanışına göre çile doldurmak üzere başka başka kılıklarda doğan ruhun her doğuştaki şekli, bağlandığı cisim, C 28, C 29, C 31, C 34, B 9, B 11-12, C 14

baĥhş (Skr. bhiksu), öğretmen, B 4, B 6, B 41, C 7, C 194, D 113, C 33, C 30, C 181-182, C 26 bodis(a)tv(a) (Skr. bodhisattva), B 33, B 46, D 17, D 26, D 46, D 71, D 81, D 87, D 94 , D 104, D 131, B 31, D 24, C 186, C 193, D 4, D 9, D 12

braman (Skr.), rahip, D 112, D 113, D 115, D 120, D 123, D 126

burĥan (Çin.) buddha, peygamber, B 33, B 42, B 45, C 186, C 197, D 96, B 35, D 3

buşı // buşi (Çin. pu-shi), sadaka; altı ya da on faziletten biri, B 28, C 92, C 116 çadik (?) B 43

çambudivip (Skr. jambudvipa), Bu dünyanın adı, C 40

Dantipali (Skr. dantipala), Özel ad, D 41, D 48, D 54, D 63, D 98, D 104, D 125-126, D 155, D 168, D 174

divdar (Skr. devadâru), Çama benzer bir ağaç, B 22

Hormuzta (Soğd.) Hormuzda teijri, Buddhizm dininde İndra: bir ilah ismi, B 53

irbiç, irbiz (?) vaşak, D 6, D 11, D 50, D 121

Kormuzta (Soğd.) Bir teijrinin adıdır, D 93, D 135.

ķunçuy (Çin. kung-çu), prenses, D 89

k(a)rmapat (Skr. karmapatha), Yeniden doğmaların çoğalmasına ve cennete ulaşmanın gecikmesine sebebiyet veren nefsaniyet, C 191

kent (Soğd. kanth), şehir, C 149 
kşan (Skr. kşana), k1sa vakit, an, D 35

küntki (Çin. k’uen), harem dairesi, C 149

linĥua (Çin. lien-hua), lotus çiçeği, B 52

madar (Moğ. matar), demon, şeytan, C 172

nomlamak (Soğd.), ders vermek, öğretmek, C 35, C 196

nomlug (Soğd.), kanunî, B 17, D 29

orohitk (Skr. rohita?), Bir çeşit balık, D 119

Patmavati (Skr. padmavati), Kız özel adı, B 46, B 56

ptr (Skr. pattra), kitap sayfas1, varak, B 30-31, C 33-34, C 99-100, C 165-166, D 35-36, D 99-100, D 138-139

purohiti (Skr. purohita), ev rahibi, C 3, C 6

rakşas (Skr. rakşasa), şeytan, C 88

sansar (Skr. samsara), mevcudiyetin deveranı, C 36

stragastriş (Skr. trayastrimsat), semalardan birinin adı, D 139

şakimuni (Skr. şakyamuni), lakaptır, tarihi Buddha'nın soyadı. B 45

şastr (Skr. şastra), tefsir, mezhep ve akaid kitabı, B 44

şastrapiryi (Skr. Şastrapriya), erkek adı, B 41

şastrarkariki (Skr. şasirakaraka), özel ad, C 38

tamu (Soğd. tamu), cehennem, C 17, C 157, C 154, C 172

tamuluk (Soğd. tamu + T. -luks), cehennemlik, cehennemde bulunan, C 20-21

titsi (Çin. ti-tse), irfanda (Buddhist mezhebinde) ilerlemek, ermek isteyip baḩ̂şdan ders alan, C 22, C 32, C 195, B 41

tujit (Skr. tuşita), en yüce cennetlerin biri, B 19

upasi (Soğd. upâsi; Skr. upâsaka), Buddhizme mensup fakat rahipler arasına girmeyen erkek, C 36

vçri (Skr. vajra), şimşek, yıldırım, B 54

\subsection{3. Çaştani Bey Hikâyesi’nde Tespit Edilen Yabancı Kökenli Sözcükler}

agnikişi (Skr. agnikeşa), Şeytanlardan birinin özel adı, 111

azun (Soğd. ajun), âlem, dünya, 45

bintipal (Skr. bhindipâla), mizrak, 237

Bodistv (Skr. Bodhisattva), "pek yüksek erenler” gibi bir anlamda olup lakap olmakla ait olduğu isimden sonra gelir. 167, 217, 246, 247, 248, 257, 263, 287, 291

btraklb (Skr.bhadrakalpa), US' deki batra ve kalp maddelerinin tariflerinden kestirildiğine göre, aslı Sanskritçe Bhadrakalpa olup "bhadra (adlı kraliçenin) zamanında" manasındadır, 262

burĥan (Çin.), Buddha, Peygamber 263, 271

burhanlıg (Çin. burhan + T. -lìg), mukaddes, ilahi 280

buyan (Skr. punya), kut, saadet. 270 
çitraviri (Sanskritçeden geldiği iddia edilmektedir.) Hint mitolojisinde İndra ilahın oğlunun öz adıdır. (Metinde, Hormuzda tanrının oğlu olarak gösteriliyor.) 241

çkir (Skr. çakra), çarh, tekerlek 237

drzul // trzul (Skr trişula), Yabaya benzer üç dişli alamet. 9, 39, 236

Duşta (Skr.), Kötülük, şeytanlardan birinin adıdır. 137, 151

erdini (Skr. ratna), cevher, kıymetli eşya, 214, 301

Ezrua Bir tanrının adıdır. 210

Haimavadi Bir şeytanın adıdır. 300.

intradana İndra tanrının yayı. 243

kalaşotari (Skr.) Bir şeytanın adı, 88

kamrakti (Skr. kâmarakta), Bir lakaptır, 230

ķavşiki "İndras” nam ilahın lakabıdır, 211

kisari (Skr. kesarin), Arslan, 215

kुolti (Skr. kati), Milyonlarca, hadsiz, hesapsiz 209, 294, 209

ķoijkyu (Çin.), çalg1 aleti, 164

Kormuzta (Soğd.) Hormuzta İndra ilahı, 217, 241

kşatrik (Skr. Kşatriya), Hintlilerde askerî sınıfa mensup olanlar, 16.

lapķıtg (?) 183

madar (Moğ. matar), Şeytan, 306.

maitri (Skr. maitreya), Özel isim, 246, 248, 288, 291

Nirvan Nirvana, Buddhizm mezhebine göre cennet 278

pançiki (Skr. paijçika), Şeytan ad1, 300

prmanu (Skr. paramânu), Atom, 253

ptr (Skr. pattra), kitap sayfas1, varak, 98, 150, 151

rakşas // rakşaz (Skr. rakşasa), şeytan ve (Skr. rakşasi) dişi şeytan, 66, 126, 130, 138, 151, 152, 157, 173, 110, 305, 137, 163, 129, 171, 304, 82, 187, 191, 209

sansar (Skr. samsara), mevcudiyetin deveran1, 264

Satagiri Şeytanlardan birinin adıdır, 300

sit satan (Skr. siddhi sadhana), yüksek sihir formülleri 269

Stayastriş (Skr. trayastrimşat), Semalardan birinin adı, 197

Tariçanta (Skr. trijata), Rakşasilerden birinin adı, 157, 171

Uçayan (Skr. ujjayini), Şehir adıdır, 1

Uru (Skr.) Şeytanlardan birinin adı, 110

Urumiki (Skr.) Şeytanlardan birinin adı, 47

vjir (Skr. vajra), Şimşek, 266

vruni (Skr. varuna), İlah adıdır, 229

Yaşomaitri (Skr. Yaşomitra), Peygamberlerden biri, 217, 246, 249, 286 


\section{Sonuç}

Uygur Türkleri, girdikleri farklı sosyal çevrelerle beraber birçok eseri Türkçeye tercüme etmişler ve karşılaştıkları yeni kavram alanlarını adlandırmak için Türk dilinin yapısına uygun sözcük türetme faaliyetleri gerçekleş̧irmişlerdir. Bunun yanı sıra, karşılaşıłkları yeni kavram alanlarında çoğunlukla özel isim olarak karşılarına çıkan sözcükleri o kavramın ait olduğu dilden ödünçleme yoluyla almışlardır. Yukarıda da görüldüğ̈̈ Kuanşi İm Pusar adlı eserde 38 Sanskritçe, 9 Soğdca ve 10 Çince olmak üzere toplamda 56 madde başı sözcük listelenmiştir. Uygurca Üç Hikâye adlı eserde, 23 Sanskritçe, 9 Soğdca, 6 Çince, 1 Moğolca, 1 Toharca ve 4 kökeni tespit edilemeyen sözcükle beraber toplamda 44 madde başı sözcük tespit edilmiştir. Çaştani Bey Hikâyesinde, 30 Sanskritçe, 3 Çince, 2 Soğdca, 1 Moğolca ve 7 kökeni tespit edilemeyen sözcükle beraber toplamda 43 madde başı sözcük tespit edilmiştir.

Buradan yola çıarak, yeni dâhil olunan sosyal çevrede Buddhizm inanç sistemine ait eserlerin Türkçeye çevrilirken özel isimler ve terim olarak kabul edilebilecek sözcükler dışında hiçbir sözcüğün ödünçleme yolu ile alınmamış olması, Türk dilinin morfolojik yapısına uygun sözcük türetme faaliyetleri ile eserlerin Türkçeye çevrilmesi dikkat edilmesi gereken bir husustur.

Bu çalı̧̧mayla, Buddhist çevre Eski Uygur Türkçesi metinlerinden Kuanşi İm Pusar, Uygurca Üç Hikâye ve Çaştani Bey Hikâyesi adlı eserler esas alınarak ödünçleme yoluyla alınan sözcükler tespit edilmeye çalışılmış ve alınan söz konusu bu sözcüklerin dâhil olunan inanç sistemi ile Uygur Türklerinin karşılaştıkları yeni kavram alanına dair ihtiyaçtan kaynaklandığı ifade edilmiştir. Sözcük türetme faaliyetlerinin en işlek ve etkin yapıldığı Eski Uygur Türkçesi döneminde ödünçleme sözcüklerin özel isimler ve terimler olarak tespit edilebiliyor olması bu dönemdeki türetme faaliyetlerinin Türk dili tarihinde önemini vurgulamaktadır.

\section{KISALTMALAR}

bk. Bakınız

Çin. Çince

Moğ. Moğolca

Skr. Sanskritçe

Soğd. Soğdca

Toh. Toharca

US Ahmet Caferoğlu, Uygur Türkçesi Sözlüğü

\section{Kuanşi İm Pusar'da Kullanılan Kısaltmalar}
A A Nüshası (St. Petersburg'da bulunan nüsha)
B B Nüshası (F. W. K. Müller tarafından iki parça halinde yayınlanan nüsha)
D D Nüshası (Mainz İlimler ve Edebiyat Akademisinde 289 (TII Y. 54-a) numarada kayitlı olan nüsha 


\section{Uygurca Üç Hikâye'de Kullanılan Kısaltmalar \\ B Uygurca Üç Hikâyede Maymunlar Beyi Hikâyesi \\ C Uygurca Üç Hikâyede Dantipali Bey Hikâyesi \\ D Uygurca Üç Hikâyede Mukaddes Tavşan Hikâyesi}

\section{Kaynaklar}

Akalın, Mehmet, Eski Türkçenin Grameri. Ankara: Türk Dil Kurumu Yayınları, 2007.

Arat, Reşit Rahmeti, “Uygur Alfabesi”, Makaleler, I, Ankara 1987, s. 674-699.

Caferoğlu, Ahmet, Eski Uygur Türkçesi Sözlüğ̈̈. İstanbul: Edebiyat Fakültesi Basımevi, 1968.

Çelik, Neslihan, Buddhist Çevre Eski Uygur Türkçesi Metinlerinde Tabâbet. Yüksek Lisans tezi, Mimar Sinan Güzel Sanatlar Üniversitesi, 2012.

Edgerton, Franklin, Buddhist Hybrid Sanskrit Grammar and Dictionary. Volume II: Dictionary, Delhi: Motilal Banarsidass, 1977.

Eraslan, Kemal, Eski Uygur Türkçesi Grameri. Ankara: Türk Dil Kurumu Yayınları, 2012.

Eraslan, Kemal, Mecâlisü’n-Nefâyis. Ankara: Türk Dil Kurumu Yayınları, 2001.

Ercilasun, Ahmet Bican, Başlangıçdan Yirminci Yüzyıla Türk Dili Tarihi. Ankara: Akçağ Yayınları, 2017.

Ercilasun, Ahmet Bican, Ziyat Akkoyunlu, Divânu Lugâti 't-Türk. Ankara: Türk Dil Kurumu Yayınları, 2014.

Gabain A. von, F. W. K. Müller, Çaştani Bey Hikâyesi. Çeviren S. Himran. İstanbul: Bürhaneddin Erenler Basımevi, 1945.

Gabain A. von, F. W. K. Müller, Uygurca Üç Hikâye. Çeviren S. Himran. Ankara: Türk Dil Kurumu Yayınları, 1946.

Tekin, Şinasi, Uygurca Metinler I: Kuanşi İm Pusar. Erzurum: Atatürk Üniversitesi Yayınları, 1960.

Togan, Zeki Velidi, Umumî Türk Tarihine Giriş, 2 cilt. İstanbul: Enderun Kitabevi, 1981. 